\title{
The ground beneath your feet: digital elevation data for today and tomorrow
}

\author{
$\underline{\text { J.C. Gallant }}^{\mathrm{a}}$ \\ ${ }^{a}$ CSIRO Land and Water, Clunies Ross St, Black Mountain, ACT 2600 \\ Email: john.gallant@csiro.au
}

\begin{abstract}
Digital elevation models (DEMs) are fundamental data infrastructure that support a large range of applications in environmental modelling. The distribution of solar radiation, patterns of wetness and water movement, mobility of animals and evolution of soils are all intimately linked to topographic form. DEMs for the Australian continent have progressed from $1 / 10^{\text {th }}$ degree resolution in 1982 to $1 / 40^{\text {th }}$ degree in 1991,9 second $\left(1 / 400^{\text {th }}\right.$ degree) in 1996 and now 1 second (about $30 \mathrm{~m}$ ) derived from the NASA Shuttle Radar Topographic Mission (SRTM). Each improvement in resolution and accuracy enables new applications as more detail and structure are revealed.
\end{abstract}

The 1 second SRTM-derived DEMs for Australia are now publicly available through the Geoscience Australia National Elevation Data Framework (NEDF) portal (http://nedf.ga.gov.au). The raw SRTM data has been processed through a series of steps to provide several products suitable for different purposes:

- DEM-S is a bare-earth elevation model with stripes and voids removed, offsets due to trees treated and noise substantially reduced in flatter areas by adaptive smoothing, which is suitable for most applications where connectivity of flow is not the primary concern such as calculation of slopes and topographic position

- DEM-H is a hydrologically conditioned elevation model derived from DEM-S with drainage enforcement using 1:250,000 scale stream lines, which is suitable for applications where hydrological connectivity is of primary concern such as calculation of contributing areas and catchment delineation

- DEM is the pre-cursor to DEM-S before adaptive smoothing, which may be useful when the retention of detail is more important than smoothness.

There is also a cleaned digital surface model (DSM) that is the precursor to DEM-S before tree offsets are removed, which is restricted to Australian government use only.

Most users of DEMs need information about the shape of the landscape, not just height, so we are producing a set of standard derived products including slope, aspect, curvatures, topographic position, relief, contributing area and wetness index. These derived surfaces are key inputs for continental scale prediction of soil properties and ecological patterns. Predictions of a suite of key soil properties on a 3 second grid for the Australian continent, using the 1 second terrain layers, are being developed and will contribute to the GlobalSoilMap.net global grid of soil properties. Catchments and stream lines derived from DEM-H will form the basis for future versions of the Australian Hydrological Geospatial Fabric (http://www.bom.gov.au/water/geofabric/index.shtml).

Digital elevation data continues to improve as measurement technology improves. Airborne lidar already provides high precision terrain data with vertical accuracy of $20 \mathrm{~cm}$ or better at $1 \mathrm{~m}$ horizontal resolution or better. This data is available in parts of Australia where the better accuracy justifies the high cost, such as urban areas, coastal lowlands, wetlands and floodplains. We need to develop ways of using high resolution data covering limited areas in combination with lower resolution data covering the continent.

New global DEMs are being acquired and will replace SRTM in the years ahead. The TANDEM-X satellite radar system will potentially produce global elevations at 2-3 times better resolution and accuracy than SRTM, and other systems will follow. Higher resolutions bring further technical challenges, not least in data volume: each 1 second DEM product for Australia is a $40 \mathrm{~GB}$ dataset and finer resolutions will be correspondingly larger.

Keywords: Digital elevation models; radar; terrain attributers; soil properties 


\section{INTRODUCTION}

A digital elevation model (DEM) is one of the fundamental pieces of information needed to understand and manage the land and DEMs are gradually replacing topographic maps as the primary and authoritative source of terrain information in Australia and across the world. DEMs are used for quantitative analysis of surface shape in the earth sciences, for deriving accurate contributing areas and catchment boundaries, modelling solar radiation and water movement, interpreting broad-scale geological features, calculating coverage of radio transmitters, visualisation of the landscape (as exemplified by Google Earth), computer gaming and for many other purposes.

The first digital elevation model of the Australian continent was produced at $1 / 10^{\text {th }}$ degree resolution (about $10 \mathrm{~km}$ ) by Moore and Simpson (1982) from about 320000 points measured during a continentwide gravity survey by the Bureau of Mineral Resources (Hutchinson and Dowling, 1991). This was succeeded in 1991 by a $1 / 40^{\text {th }}$ degree DEM (about $2.5 \mathrm{~km}$ ) that incorporated about 580000 elevation points and stream lines digitised from the 1:2.5M scale map of Australia (Hutchinson, 1989; Hutchinson and Dowling, 1991). In 1996 the first 9 second (about $250 \mathrm{~m}$ ) resolution DEM was produced from 1:250k and 1:100k mapping (Hutchinson, 1996; Carroll and Morse, 1996), and was used for many purposes including the National Land and Water Resources Assessment (NLWRA) around 2000. Substantial revisions to both data and methods (Hutchinson, 2000) have resulted in versions 2 and 3 of the 9 second DEM (Hutchinson, 2011; ANU Fenner School of Environment and Society and Geoscience Australia, 2008).

In February 2000 NASA flew the Shuttle Radar Topographic Mission (SRTM), a Space Shuttle mission utilising interferometric synthetic aperture radar (IfSAR) technology to capture near-global elevation data at a resolution of 1 second, about $30 \mathrm{~m}$ (Farr et al., 2007). While this data has its imperfections, it provides the best basis for a finer resolution continental DEM to succeed the 9 second DEM.

These developments in continental elevation models have been paralleled at the state and territory level by the development of finer resolution regional elevation models and a shift from topographic mapping to direct measurement as source data. DEMs at 20 or $25 \mathrm{~m}$ resolution were produced by several states and territories in the 1990 s or earlier based on topographic mapping mostly at 1:25 000 scale. More recently finer and more accurate DEMs have been produced for some areas using airborne laser scanning (ALS or lidar) and photogrammetric techniques. Today these technologies typically produce DEMs with $1 \mathrm{~m}$ resolution and a vertical error of $20 \mathrm{~cm}$ or better.

Figure 1 demonstrates the substantial improvement of resolution and detail in the 1 second SRTM data compared to the 9 second DEM, and also highlights two of the artefacts that impact on SRTM data quality: height offsets due to trees and random noise. Other artefacts not visible in Figure $1 \mathrm{~b}$ are systematic striping, voids and height offsets due to built structures. Treatments have been developed for most of these artefacts that, when combined with drainage enforcement, yield the hydrological DEM-H (Figure 1c) that is suitable for use in water information applications.

This paper briefly describes the treatments developed to produce these improved DEMs from the SRTM data and considers likely future trends in DEMs for Australia and the globe.
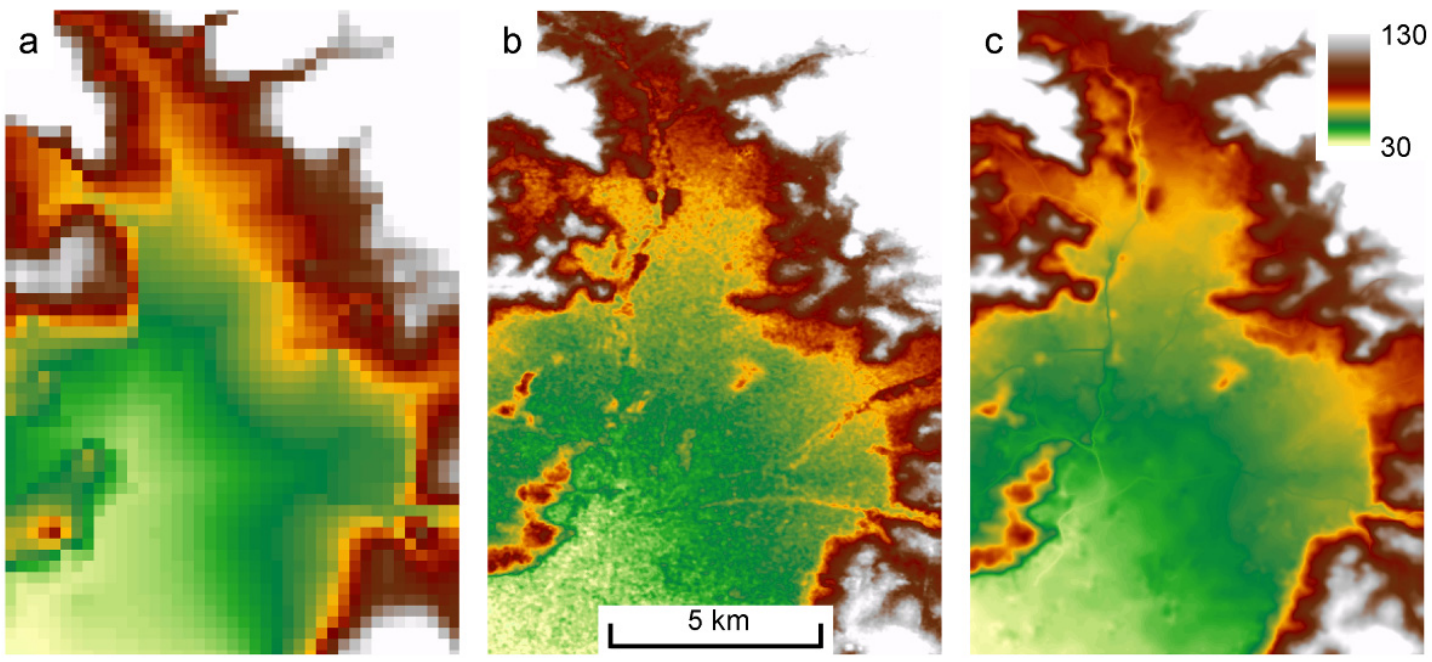

Figure 1. Comparison of (a) 9 second, (b) original 1 second SRTM and (c) 1 second DEM-H around Bunyip, south-eastern Victoria, $145.8^{\circ} \mathrm{E} 38.0^{\circ} \mathrm{S}$ 


\section{REMOVING ARTEFACTS AND NOISE FROM THE SRTM DEM}

\subsection{Removing Stripes and Voids to Produce the DSM}

Diagonal stripes are detectable in the SRTM data to varying degrees in all low relief areas of Australia. This striping is a side-effect of the Scan-SAR method of data acquisition (Farr et al., 2007) and appears as regular variations in height with a wavelength of about $800 \mathrm{~m}$ aligned with orbital paths of the Space Shuttle. Voids - areas without any data - occur where reflected radar signal levels were too low to provide reliable elevation data or where steep terrain causes radar shadows.

The striping was detected and removed using a 2-dimensional Fourier transform method (Read et al., in prep). The spatial frequencies corresponding to the striping were manually identified in $1 / 4 \times 1 / 4$ degree tiles and those frequencies were removed from the elevation data. The striping takes on complicated forms in some areas where multiple acquisitions from different orbits overlap, producing two or more sets of stripes at different angles and amplitudes.

Voids were treated using a modification of the Delta Surface Fill method (Grohman et al., 2006) which inserts elevation data from another source into the voids after adjusting the elevations to match SRTM elevations at void edges; the 9 second DEM was used as infill as it was the best available continental data (Read and Gallant, in prep). The cleaned SRTM data after stripe and void removal is named the DSM (digital surface model).

\subsection{Removing Tree Offsets to Produce the Bare-Earth DEM}

The radar used to collect SRTM data could not penetrate trees to measure ground heights so elevation offsets occur wherever there is sufficiently dense tree cover. This is particularly apparent and problematic in very flat areas where the tree offsets create elevation differences much larger than the topographic relief. Trees along watercourses are common in much of Australia, producing apparent ridges where there should be channels and leading to serious errors in estimated water flow pathways. Similar offsets occur due to larger built structures and are visible in city centres and for some other features such as large power transmission pylons: these offsets have not been removed.

Tree offsets were treated by (Gallant et al., in prep):

- Identifying areas covered by trees using several land-cover classifications at 1 second resolution derived from Landsat imagery

- Estimating the height of the tree offset at boundaries between tree-covered and clear ground

- Interpolating the estimated height offsets through the tree-covered areas and subtracting the estimated offsets from the DSM to derive bare-earth elevations.

Figure 2 shows part of the area in Figure 1 where tree offsets are clearly visible, before and after treatment. The quality of the treatment is limited by mismatches between the SRTM response to vegetation and the mapping from imagery, including the effects of clearing and planting when the imagery was not acquired at the same time as the SRTM.

A by-product of the tree offset removal was a map of tree offsets across Australia which is related to tree heights. This information is expected to be a useful adjunct to other vegetation information, although it is limited to a single snapshot in February 2000.

\subsection{Adaptive Noise Removal to Produce the Smoothed DEM-S}

The bare-earth DEM still contains random noise with an amplitude of between 1 and $5 \mathrm{~m}$, which is clearly visible as blotchy colour variations in the flatter areas of Figure 2c. In steeper areas this is of little consequence but in the flatter areas it causes errors in measures of surface shape such as slope, curvature and flow direction. An adaptive smoothing method was developed that smooths more aggressively where the height variations are comparable to the noise amplitude and less, or not at all, where the height variations are much larger than the noise. The noise amplitude was estimated directly from the DSM. The adaptively smoothed DEM-S (Figure $3 \mathrm{~b}$ ) provides more reliable estimates of slope and other terrain attributes (Gallant, 2011) as well as supporting the derivation of elevation contours. 

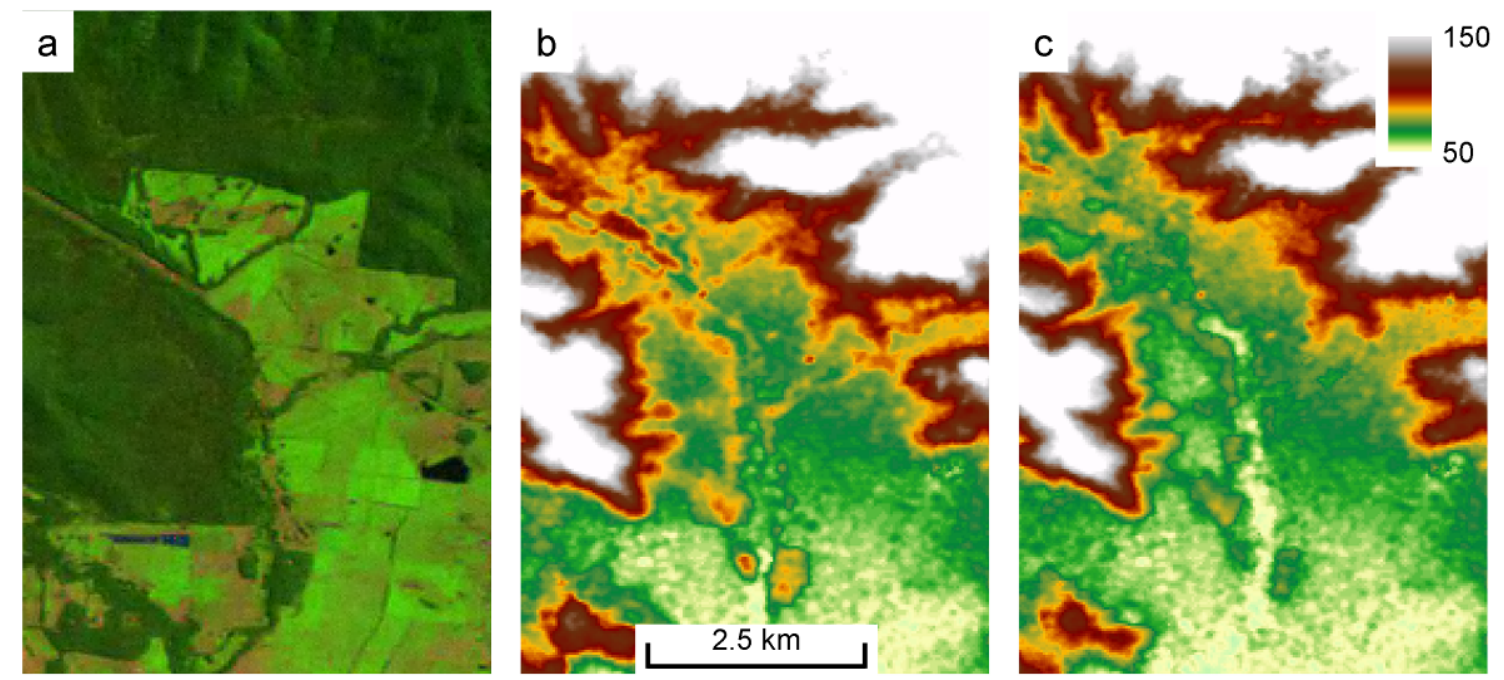

Figure 2. An area from Figure 1 showing (a) tree cover visible in Landsat imagery, (b) digital surface model with tree offsets and (c) DEM after removal of tree offsets
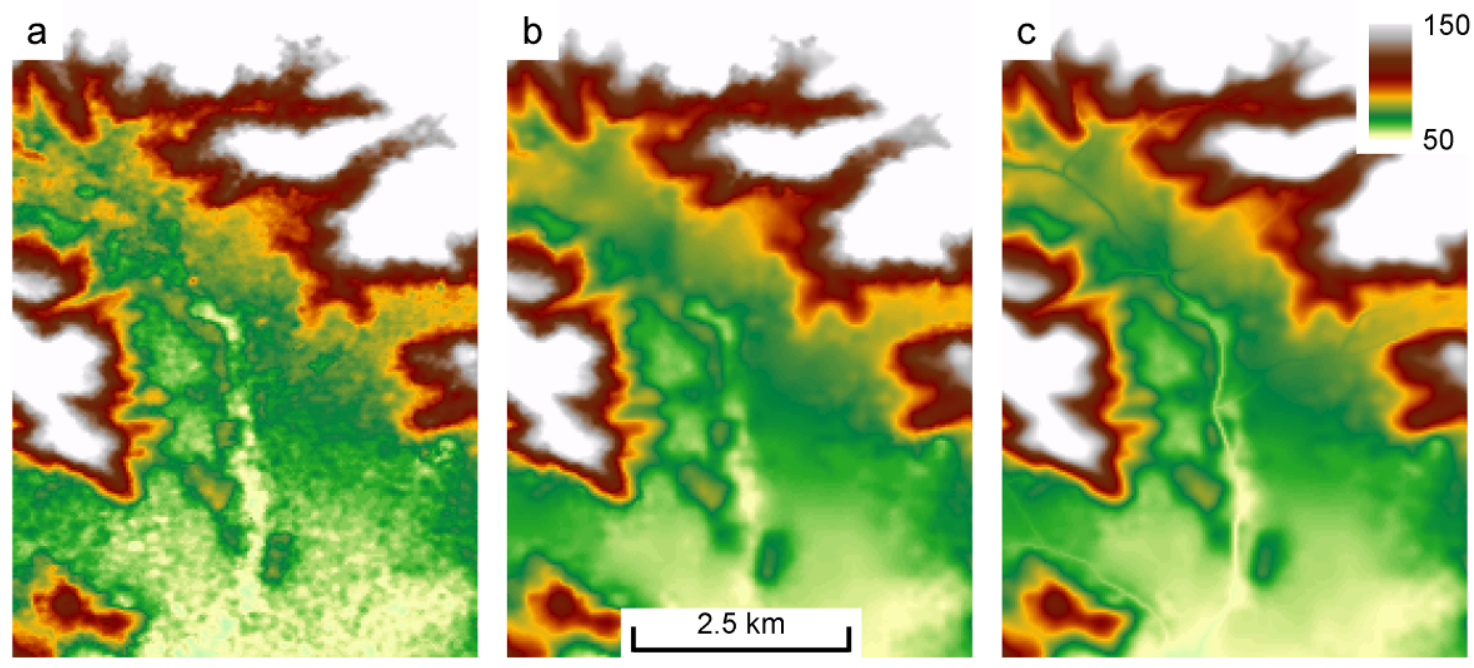

Figure 3. The area in Figure 2 showing (a) DEM, (b) DEM-S after adaptive noise removal and (c) DEM-H after drainage enforcement using ANUDEM and 1:250,000 scale mapped stream lines

\section{DRAINAGE ENFORCEMENT TO PRODUCE THE HYDROLOGICAL DEM-H}

While the smoothed DEM-S provides a much improved representation of the terrain shape it fails to capture channels except where they are quite large. This is largely due to the limited resolving power of the SRTM radar system but is compounded by the frequent obscuring of river channels by riparian trees. While the general offset due to trees can be removed, the hidden topographic structures under the trees cannot be recovered.

To produce a DEM with suitable hydrological connectivity a drainage enforcement process was applied using national 1:250,000 scale mapped stream lines (Geoscience Australia, 2011). The ANUDEM program (Hutchinson, 1989; Hutchinson, 2000; Hutchinson, 2011) was chosen to perform the drainage enforcement, and was adapted to accommodate the particular characteristics of the dense and noisy SRTM data (Hutchinson et al., 2011).

The 1:250,000 scale stream lines have a spatial accuracy of about $200 \mathrm{~m}$, considerably coarser than the $\sim 30 \mathrm{~m}$ resolution of the SRTM elevation data. Where the landscape is quite flat the spatial offsets do not cause significant problems other than the positional error, but in steep areas the offsets result in the mapped stream lines falling on hillslopes and ridges rather than in the bottoms of valleys. Fortunately, in the steeper areas the mapped stream lines are less critical because the correct location and direction of watercourses can be identified in the DEM. 


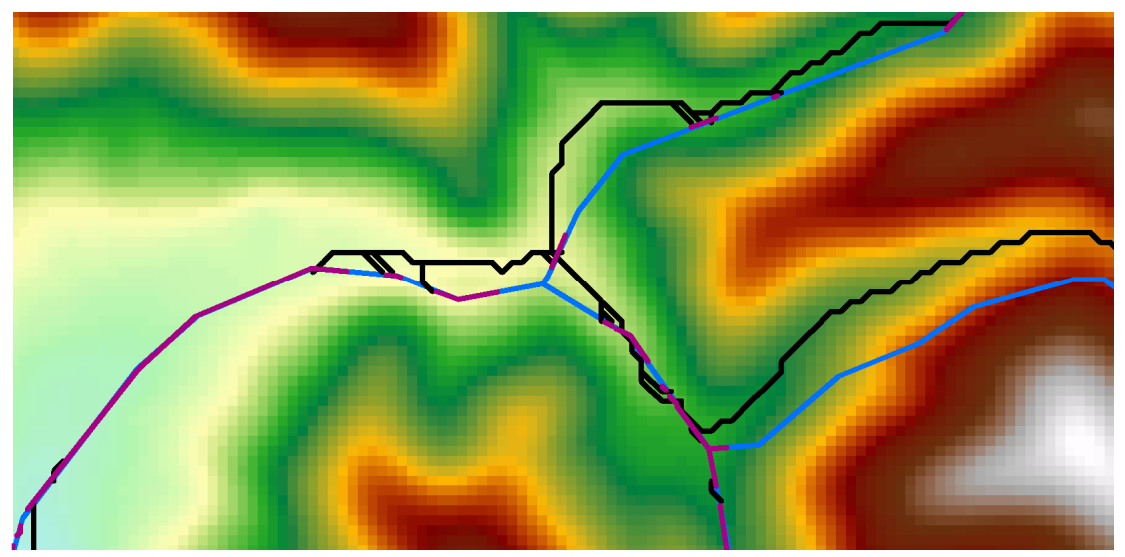

Figure 4. Mapped 1:250k scale stream lines (blue), retained mapped lines (purple) and replacement DEM-derived stream lines (black) in a high relief area in northern Victoria, $147.52^{\circ} \mathrm{E} 36.51^{\circ} \mathrm{S}$

Methods were developed to determine where the mapped stream lines should be retained or removed, and to fill in the resulting gaps using flow lines derived from DEM-S (Dowling et al., in prep). Figure 4 shows retained and removed 1:250,000 scale mapped stream lines and the infilling lines, and the resulting drainage-enforced DEM-H. Figure 3c shows the DEM-H in the flatter landscape in southern Victoria. Finer scale stream mapping produced by state agencies is currently being compiled by Geoscience Australia and will be incorporated into subsequent versions of DEM-H over the next 1-2 years, producing further improvements in quality.

\section{DERIVED TERRAIN ATTRIBUTE LAYERS}

For most applications it is the shape of the surface, not the actual elevation, that is important. Shape is represented by a variety of derived topographic attributes: slope, aspect, curvature, flow accumulation, topographic position and so on. A range of these attributes has been derived from either DEM-S or DEM-H and will be made available for download through Geoscience Australia.

Catchments and stream networks extracted from the DEM-H will progressively be incorporated into the Bureau of Meteorology's Australian Hydrological Geospatial Fabric (http://www.bom.gov.au/water/geofabric/index.shtml) to provide an authoritative source of information for models that show how water is stored, transported and used through the landscape.

The Soil and Landscape Grid of Australia (http://www.tern.org.au/Soils-and-Landscape-Grid-ofAustralia-pg17731.html), one of the facilities within TERN, Australia's Terrestrial Ecosystem Research Network, is using these terrain attributes to produce a suite of predicted soil physical and chemical properties across Australia. This will also form the core of Australia's contribution to the Global Soil Map (http://www.globalsoilmap.net/). The terrain attributes also provide the physical environmental information needed to map ecosystems and species distributions.

\section{CONTINENTAL DEMS INTO THE FUTURE}

While the SRTM DEM is a significant improvement over previous global DEM products there are many applications that require better quality data, such as flood and coastal inundation modelling where vertical precision much better than 1 metre is required. Better data will come over time through a combination of improved global DEMs and the use of higher quality local data. The historical trend of about 10 times finer resolution each decade is unlikely to continue for several reasons: the benefits of finer resolution become progressively less with increasing refinement; the growth in data size threatens to outstrip our ability to process it; and the measurements themselves becomes more expensive with finer resolution and higher accuracy. The current resolution of $30 \mathrm{~m}$ is adequate for many purposes, since it is just fine enough to capture shapes at the scale of hillslopes.

\subsection{Better Global DEMs}

ASTER G-DEM (Toutin, 2008; http://asterweb.jpl.nasa.gov/gdem.asp) was developed from stereo pairs of satellite images using standard photogrammetric methods and provides a 1 second $(30 \mathrm{~m})$ resolution elevation model of the globe. While this is considerably finer than the publicly released 3 second $(90 \mathrm{~m})$ SRTM data, evaluations of the product have found that it contains less detail than the 
SRTM product and is plagued by artefacts that limit its usefulness (e.g. Hengl and Reuter, 2011). An improved product (version 2) is expected to be released in late 2011 with better resolution (but higher noise) and fewer artefacts (http://www.ersdac.or.jp/GDEM/E/4 1.html). To date, the ASTER G-DEM is primarily seen as a supplement to SRTM rather than a replacement.

TanDEM-X and TerraSAR-X are a pair of satellites currently collecting radar data similar to the SRTM system but with higher spatial resolution (http://www.infoterra.de/tandem-X dem). While data has not yet been made available, the project team are expecting to produce a global DEM in 2014 with about $12 \mathrm{~m}$ resolution and a vertical accuracy better than $2 \mathrm{~m}$ relative and $10 \mathrm{~m}$ absolute (relative accuracy refers mainly to random errors between adjacent values and affects measures of local surface shape, while absolute accuracy refers to systematic errors compared to established heights). The improvement in horizontal resolution is quite significant compared to the $90 \mathrm{~m}$ resolution of the publicly released SRTM DEM. The claimed vertical error is about half that of SRTM, which is a significant improvement but still does not provide the level of accuracy needed for inundation mapping and other demanding applications. Like SRTM, the TanDEM-X product will be a surface model and current plans are to process the data to a bare-earth model by manual editing (http://www.infoterra.de/tandem$\underline{\mathrm{x} \text { dem }}$, an expensive and time-consuming process. Public release of this data is unlikely in the near future.

More accurate global elevation data has been collected by the GLAS laser altimeter on the ICESat satellite (http://icesat.gsfc.nasa.gov/icesat/), but this instrument records repeated measurements along widely separated tracks rather than the uniform dense coverage required for a DEM. A space-borne scanning laser altimeter does not appear to be technically feasible at present.

\subsection{The Role of Local Accurate DEMs}

The most accurate and detailed DEMs available come from airborne scanning laser altimetry, photogrammetry and radar, with horizontal resolution of $1 \mathrm{~m}$ or better and vertical accuracy of $50 \mathrm{~cm}$ or better (and even finer data is collected by terrestrial scanning, but over very limited areas). Laser altimetry has the advantage of penetrating through tree cover so that ground heights can be measured under trees; it also provides information on canopy structure.

These higher resolution DEMs provide information suitable for applications like hydrodynamic modelling in floodplains: detailed topographic structure, connectivity of channels and (in dry conditions) channel bed form. But this type of data is expensive and it is unlikely that we will see uniform coverage of Australia, or even the more populated parts of the continent, by high resolution DEMs in the near future.

To take full advantage of these patches of high resolution data, they need to be connected in some way to the coarser continental DEMs so that models can operate over the whole landscape. Whatever approach is used to achieve this connection, the continuity of flow paths across the surface is of paramount importance so that the movement of water and other earth surface processes can be accurately modelled.

\subsection{Managing and Using Large DEMs}

Better horizontal resolution comes at the cost of larger data size. The $1 / 40^{\text {th }}$ degree DEM from 20 years ago contained 1681 columns by 1361 rows, about $9 \mathrm{MB}$ of floating point data; the 9 second DEM is 14297 rows by 16440 columns, about $900 \mathrm{MB}$; each 1 second DEM product consists of 813 tiles each of 3600 rows by 3600 columns, about $42 \mathrm{~GB}$ (unlike the previous DEMs the 1 second DEMs do not cover a complete rectangle over Australia). This is unwieldy data for many users and is best stored and processed on computing clusters rather than on individual PCs. Increasing the resolution to the $12 \mathrm{~m}$ of TanDEM-X increases this to $260 \mathrm{~GB}$.

Many users will only need a portion of the continental DEM, which is one of the reasons the tile structure of the original SRTM data has been retained, and initiatives like the NEDF Portal (http://nedf.ga.gov.au) are making it easier to access. Web services are likely to play an increasingly important role in linking data to models, so that model users do not need to manually assemble the data layers required by a model. Access to the 1 second DEMs through a web service interface is currently under development. 


\section{CONCLUSIONS}

Digital elevation models play a fundamental role in our understanding of the natural environment and they continue to improve as better measurement technologies are developed. Both horizontal resolution and vertical accuracy have improved progressively with 1 second (about $30 \mathrm{~m}$ ) representing the current state of the art for global and continental data. For many purposes, this $30 \mathrm{~m}$ resolution is a 'sweet spot' with enough resolution to capture shapes at the hillslope scale and a data volume that is - barely manageable. Further improvements in vertical accuracy are more important than horizontal resolution for many purposes, particularly those involving inundation by water in floodplains and coastal zones. To extract maximum value from available data we need ways of combining continental data with higher resolution data over limited areas as well as web-based methods for automatically linking models with data.

\section{ACKNOWLEDGEMENTS}

The development of the national 1 second SRTM-derived DEMs was funded by the Water for a Healthy Country Research Flagship and the Bureau of Meteorology, supported by Geoscience Australia and in collaboration with the Fenner School, ANU.

\section{REFERENCES}

ANU Fenner School of Environment and Society and Geoscience Australia (2008). GEODATA 9 Second DEM and D8 Digital Elevation Model and Flow Direction Grid, User Guide. Geoscience Australia, 43 pp. http://www.ga.gov.au/image cache/GA11644.pdf.

Carroll, D. and M.P. Morse (1996). A national digital elevation model for resource and environmental management, Cartography 25: 395-405.

Dowling, T.I, A.M. Read, M.F. Hutchinson and J.C. Gallant (in prep). Drainage enforcement of the 1 second SRTM DEM for Australia. To be submitted to Remote Sensing of Environment.

Farr, T.G. et al. (2007). The shuttle radar topographic mission, Reviews of Geophysics 45, RG2004, doi:10.1029/2005RG000183.

Gallant, J.C. (2011). Adaptive smoothing for noisy DEMs. Paper presented at Geomorphometry 2011, Redlands, California, 7-9 September 2011. http://geomorphometry.org/Gallant2011.

Gallant, J.C., A.M. Read and T.I. Dowling (in prep). Removing vegetation offsets from the 1 second SRTM DEM for Australia. To be submitted to Remote Sensing of Environment.

Geoscience Australia (2011). GEODATA TOPO 250K Series 3, Hydrography theme. https://www.ga.gov.au/products/servlet/controller?event=GEOCAT DETAILS\&catno=63999.

Grohman, G., G. Kroenung, and J. Strebeck (2006). Filling SRTM voids: The delta surface fill method, Photogrammetric Engineering and Remote Sensing 72(3), 213-216.

Hengl, T. and H. Reuter (2011). How accurate and usable is GDEM? A statistical assessment of GDEM using LiDAR data. Paper presented at Geomorphometry 2011, Redlands, California, 7-9 September 2011. http://geomorphometry.org/HenglReuter2011.

Hutchinson, M.F. (1989). A new method for gridding elevation and streamline data with automatic removal of pits, Journal of Hydrology 106: 211-232.

Hutchinson, M. F. (1996). A locally adaptive approach to the interpolation of digital elevation models. Presented at the Third International Conference/Workshop on Integrating GIS and Environmental Modeling, Santa Fe, New Mexico, 21-25 January 1996.

Hutchinson, M.F. (2000). Optimising the degree of data smoothing for locally adaptive finite element bivariate smoothing splines, Australian \& New Zealand Industrial and Applied Mathematics Journal 42(E): C774-C796.

Hutchinson, M.F. (2011). ANUDEM version 5.3. Fenner School of Environment and Society, Australian National University, Canberra. http://fennerschool.anu.edu.au/research/publications/software-datasets/anudem.

Hutchinson, M.F., and T.I. Dowling (1991). A continental hydrological assessment of a new grid-based digital elevation model of Australia, Hydrological Processes, 5(1), 45-58.

Hutchinson, M.F., T. Xu and J.A. Stein (2011). Recent progress in the ANUDEM elevation gridding procedure. Paper presented at Geomorphometry 2011, Redlands, California, 7-9 September 2011. http://geomorphometry.org/HutchinsonXu2011.

Moore, R.F., and C.J. Simpson (1982). Computer manipulation of a digital terrain model (DTM) of Australia, Bureau Mineral Resources Journal of Australian Geology and Geophysics, 7, 63-67.

Read, A.M., J.C. Gallant and T.I. Dowling (in prep). Removing stripes and voids from the 1 second SRTM DEM for Australia. To be submitted to Remote Sensing of Environment.

Toutin, T. (2008), ASTER DEMs for geomatic and geoscientific applications: a review, International Journal of Remote Sensing, 29(7), 1855-1875. 